\title{
ERRATUM
}

\section{Erratum for Moriguchi et al., Transkingdom Genetic Transfer from Escherichia coli to Saccharomyces cerevisiae as a Simple Gene Introduction Tool}

Kazuki Moriguchi, ${ }^{a}$ Noritaka Edahiro, ${ }^{\text {a }}$ Shinji Yamamoto, ${ }^{a}$ Katsuyuki Tanaka, ${ }^{a}$ Nori Kurata, ${ }^{b}$ Katsunori Suzuki ${ }^{a}$

Department of Biological Science, Graduate School of Science, Hiroshima University, Kagamiyama, Higashi-Hiroshima, Japana; Plant Genetics, National Institute of Genetics, Yata, Mishima, Japan ${ }^{\mathrm{b}}$

Volume 79, no. 14, p. 4393-4400, 2013. Page 4395, column 2, line 6: “10 mM” should read “80 mM.”

Page 4395, column 2, line 6: “0.5\%” should read “0.05\%.” 